\title{
Applications of "planar-chiral" heterocycles in asymmetric catalysis*
}

\author{
Gregory C. Fu \\ Department of Chemistry, Massachusetts Institute of Technology, Cambridge, MA \\ 02139, USA
}

Abstract: Planar-chiral derivatives of pyridine function as efficient catalysts for processes such as the kinetic resolution of primary amines and the desymmetrization/ring-opening of meso epoxides. Planar-chiral pyrrolyl and phospholyl derivatives serve as effective chiral ligands for a range of metal-catalyzed reactions, including the copper-catalyzed ring-expansion of oxetanes and the rhodium-catalyzed isomerization of allylic alcohols.

\section{INTRODUCTION}

At the time that we initiated our program in 1995, there were no applications of "planar-chiral" heterocycles in asymmetric catalysis (Fig. 1). During the past six years, we have been developing the chemistry of this intriguing family of molecules.

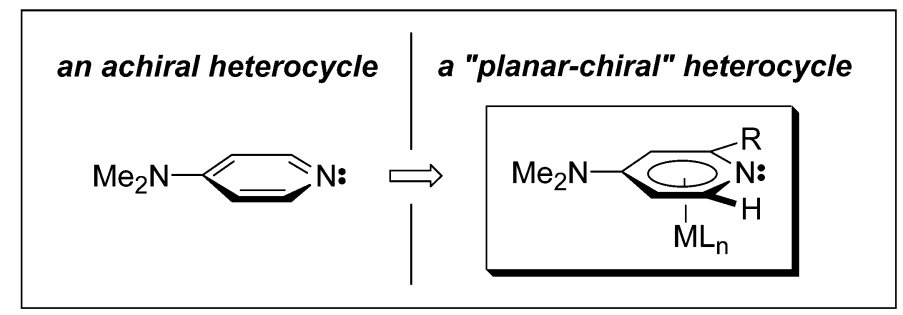

Fig. 1 From an achiral heterocycle to a "planar-chiral" heterocycle.

\section{PYRIDINE-DERIVED CATALYSTS}

Pyridines and pyridine- $N$-oxides catalyze a wide range of reactions, including the acylation of alcohols and amines, the rearrangement of $O$-acylated enolates, and the ring-opening of epoxides. Until recently, there were very few reports of asymmetric catalysis of such transformations [1].

We have synthesized an array of planar-chiral pyridine-derived complexes (e.g., Fig. 2), and we have determined that they serve as effective enantioselective catalysts for a broad spectrum of processes (Fig. 3) [2].

\footnotetext{
* Lecture presented at the $38^{\text {th }}$ IUPAC Congress/World Chemistry Congress 2001, Brisbane, Australia, 1-6 July 2001. Other presentations are published in this issue, pp. 1033-1145.
} 


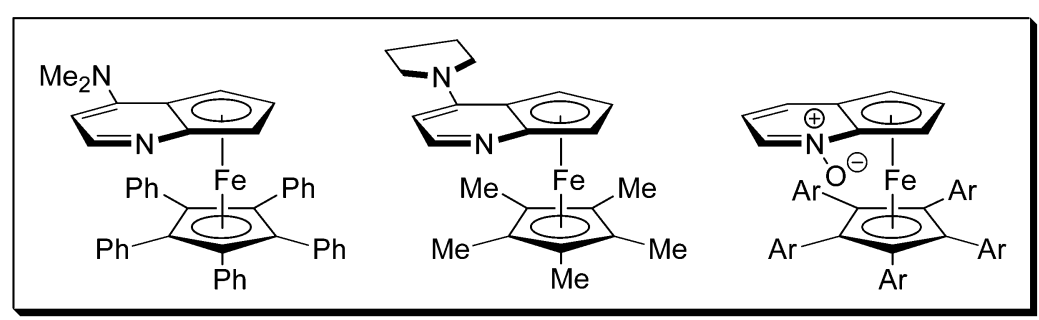

Fig. 2 Planar-chiral pyridine-derived catalysts.

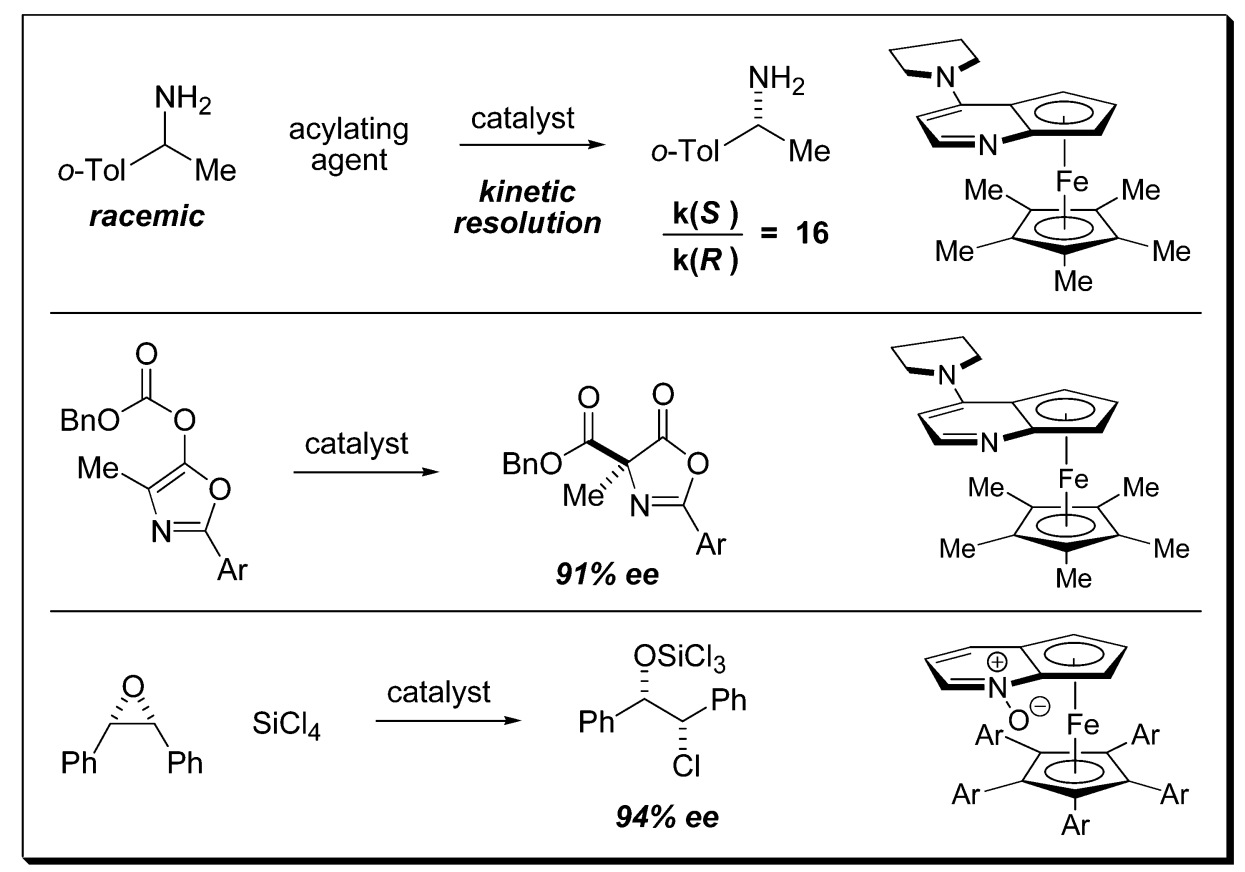

Fig. 3 Asymmetric catalysis with planar-chiral pyridine derivatives.

\section{CHIRAL LIGANDS}

We have also been exploring the use of planar-chiral heterocycles as chiral ligands for transition metals. Two examples of the ligands that we have synthesized are the bisazaferrocene and the phosphaferrocene illustrated in Fig. 4.

We have established that these new ligands are effective in reactions such as the copper-catalyzed ring expansion of oxetanes and the rhodium-catalyzed isomerization of allylic alcohols (Fig. 5) [3]. 


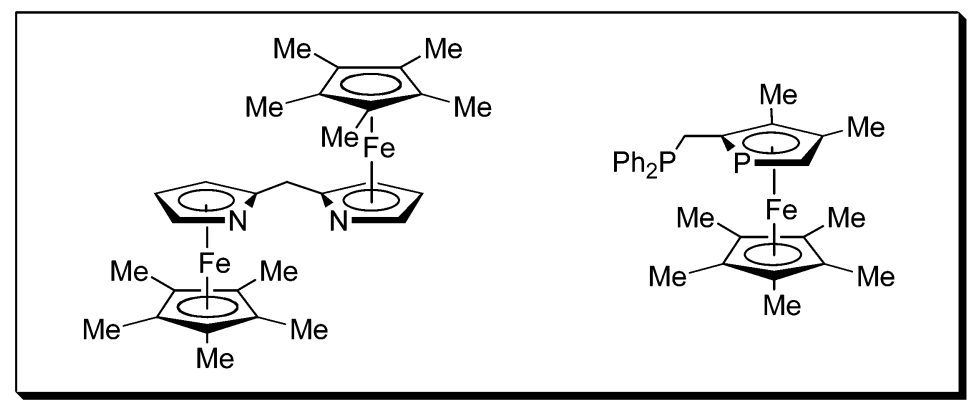

Fig. 4 Planar-chiral heterocycles as bidentate ligands for transition metals.

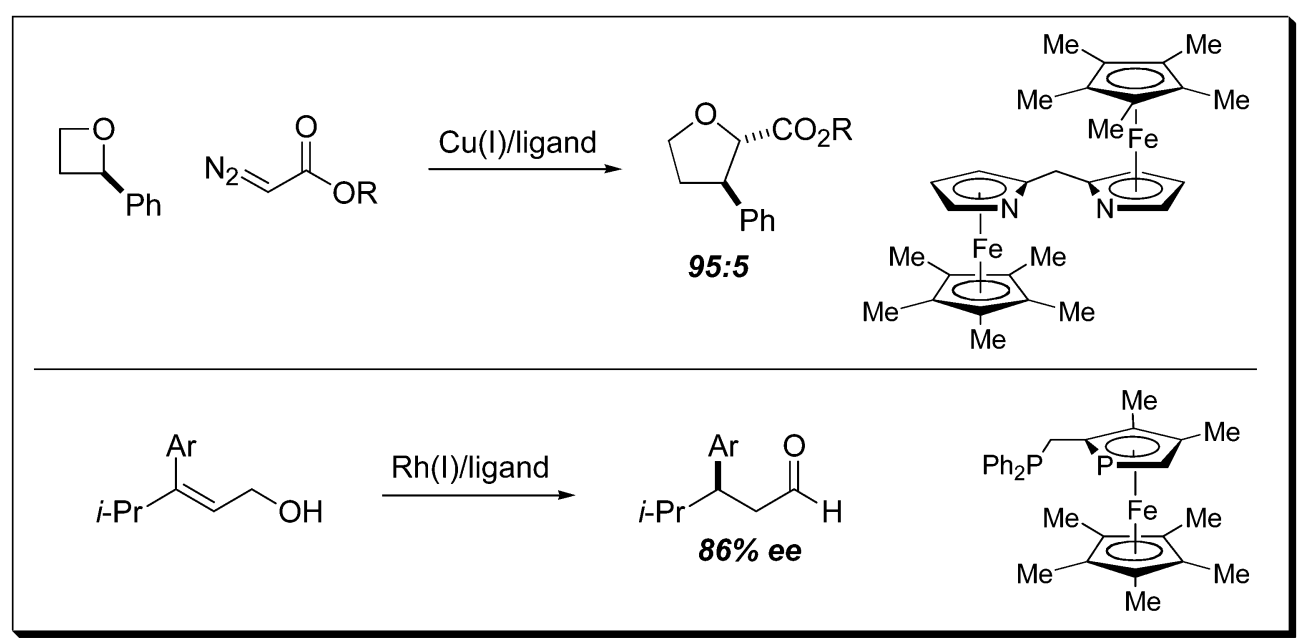

Fig. 5 Applications of planar-chiral heterocycles in transition metal-catalyzed processes.

\section{CONCLUSION}

Planar-chiral heterocycles can serve as effective chiral ligands for transition metals and as useful asymmetric catalysts in their own right. Ongoing efforts in this laboratory are directed at expanding the range of applications of this interesting family of compounds.

\section{REFERENCES}

1. For a more complete overview, see: G. C. Fu. Acc. Chem. Res. 33, 412-420 (2000).

2. (a) B. Tao, M. M.-C. Lo, G. C. Fu. J. Am. Chem. Soc. 123, 353-354 (2001); (b) S. Arai, S. Bellemin-Laponnaz, G. C. Fu. Angew. Chem., Int. Ed. Engl. 40, 234-236 (2001); (c) S. BelleminLaponnaz, J. Tweddell, J. C. Ruble, F. M. Breitling, G. C. Fu. Chem. Commun. 1009-1010 (2000); (d) M. Suginome and G. C. Fu. Chirality 12, 318-324 (2000); (e) B. Tao, J. C. Ruble, 
D. A. Hoic, G. C. Fu. J. Am. Chem. Soc. 121, 5091-5092 (1999); (f) B. L. Hodous, J. C. Ruble, G. C. Fu. J. Am. Chem. Soc. 121, 2637-2638 (1999); (g) J. C. Ruble and G. C. Fu. J. Am. Chem. Soc. 120, 11532-11533 (1998); (h) C. E. Garrett, M. M.-C. Lo, G. C. Fu. J. Am. Chem. Soc. 120, 7479-7483 (1998); (i) J. Liang, J. C. Ruble, G. C. Fu. J. Org. Chem. 63, 3154-3155 (1998); (j) J. C. Ruble, J. Tweddell, G. C. Fu. J. Org. Chem. 63, 2794-2795 (1998); (k) J. C. Ruble, H. A. Latham, G. C. Fu. J. Am. Chem. Soc. 119, 1492-1493 (1997); (1) J. C. Ruble and G. C. Fu. J. Org. Chem. 61, 7230-7231 (1996).

3. (a) M. M.-C. Lo and G. C. Fu. Tetrahedron 57, 2621-2634 (2001); (b) R. Shintani, M. M.-C. Lo, G. C. Fu. Org. Lett. 2, 3695-3697 (2000); (c) K. Tanaka, S. Qiao, M. Tobisu, M. M.-C. Lo, G. C. Fu. J. Am. Chem. Soc. 122, 9870-9871 (2000); (d) R. Rios, J. Liang, M. M.-C. Lo, G. C. Fu. Chem. Commun. 377-378 (2000); (e) M. M.-C. Lo and G. C. Fu. J. Am. Chem. Soc. 120, 10270-10271 (1998); (f) S. Qiao and G. C. Fu. J. Org. Chem. 63, 4168-4169 (1998); (g) P. I. Dosa, J. C. Ruble, G. C. Fu. J. Org. Chem. 62, 444-445 (1997). 